\title{
Hydrogen sulfide: the shutter button of stomata in plants
}

\author{
Zhuping Jin \& Yanxi Pei* \\ School of Life Science, Shanxi University, Taiyuan 030006, China
}

Received September 13,2016; accepted September 29, 2016; published online October 21, 2016

Citation: Jin, Z., and Pei, Y. (2016). Hydrogen sulfide: the shutter button of stomata in plants. Sci China Life Sci 59, 1187-1188. doi: 10.1007/s11427-016-0265-3

In the past few decades, Hydrogen sulfide $\left(\mathrm{H}_{2} \mathrm{~S}\right)$ has been newly witnessed as a third gasotransmitter with similar biological functions to its two previously identified counterparts nitric oxide (NO) and carbon monoxide ( $\mathrm{CO}$ ), after being recognized as a toxic gas with an unpleasant rotten-egg smell for hundreds of years. Following the recognition of its great pharmacological potential in mammalian (Mani et al., 2015), $\mathrm{H}_{2} \mathrm{~S}$ has also been revealed as a crucial player involved in the regulation of physiological processes in normal plants. It has also been found to be a critical messenger in plant defense responses against a variety of biotic and abiotic stresses at physiological concentrations. The $\mathrm{H}_{2} \mathrm{~S}$-synthesizing enzymes, located in various subcellular compartments such as the cytoplasm, mitochondria and chloroplast, are more abundant in plants than in animals and show a spatial-temporal expression pattern (Jin and Pei, 2015).

Eyes are the windows to the soul. Stomata, pores on the leaf surface, which are the "eyes" of plants, have been demonstrated to actively engage in various cellular aspects under different changing environmental conditions. Stomata open or close in response to environmental stimuli such as atmospheric humidity, light, atmospheric $\mathrm{CO}_{2}$ concentration and plant hormones. It has been reported that $\mathrm{H}_{2} \mathrm{~S}$ responds to drought stress by inducing stomatal closure in Arabidopsis thaliana, Vicia faba and Impatiens walleriana (Jin et al., 2011; Jin et al., 2013). The initial research was based on pharmacological experiments by applying exogenous $\mathrm{H}_{2} \mathrm{~S}$ donor (NaHS and GYY4137) (Jin et al., 2011).

*Corresponding author (email: peiyanxi@sxu.edu.cn)
Later on $A t L C D$ (L-cysteine desulfhydrase) mutants were used to provide genetic evidence to support the physiological role of endogenous $\mathrm{H}_{2} \mathrm{~S}$ on stomatal movement (Jin et al., 2013). Similarly, $\mathrm{H}_{2} \mathrm{~S}$ was also confirmed to participate in ethylene and NO-induced stomatal closure. Analysis of GUS activity from the transgenic plants harboring different fragments of the promoter indicated that the key section of AtDCD1 (D-cysteine desulfhydrase gene) promoter in response to ethylene came from -697 to -408 bp whereas the key section in response to drought stress was from -90 to -1 bp (Liu et al, 2011; Hou et al., 2016). Interestingly, another research group reported that exogenous $\mathrm{H}_{2} \mathrm{~S}$ could induce stomatal opening by reducing the accumulation of NO in guard cells of $A$. thaliana and a crop plant, Capsicum annuum (Lisjak et al., 2010). Thus, the effect of $\mathrm{H}_{2} \mathrm{~S}$ on stomatal movement remains a controversial topic. The discrepancy might be simply due to the different experimental systems and distinct features of plant materials. Under any circumstances, the consequence caused by $\mathrm{H}_{2} \mathrm{~S}$ is to ultimately enhance the tolerance of plants under abiotic stress. Induction of stomatal closure is to reduce the moisture loss under drought stress, while the purpose of stomatal opening might decrease the photorespiration and enhance photosynthesis. With this question, it is intriguing to further investigate the mechanism of stomatal movement regulated by $\mathrm{H}_{2} \mathrm{~S}$.

Regulation of the turgor of the two guard cells that surround the pore is essential to the control of stomatal aperture. Their volume and turgor are reduced by efflux of anions and potassium ions $\left(\mathrm{K}^{+}\right)$and by gluconeogenic conversion of malate into starch, which causes membrane depolarization and stom- 
atal closure. Stomatal opening, in contrast, is mediated by the increase in $\mathrm{K}^{+}$, anion and malate concentrations in the guard cells. It is therefore noted that ion channels in cell membranes have become an important way of material exchange between organisms and the surroundings, which facilitate the identification of genes encoding specific ion channels and transporters. Recent studies focused on $\mathrm{H}_{2} \mathrm{~S}$ regulating ion channels at different levels. Initially, expression of Calcium $\left(\mathrm{Ca}^{2+}\right)$ channel and outward-rectifying $\mathrm{K}^{+}$channel coding genes were found decreased with the reduction of endogenous $\mathrm{H}_{2} \mathrm{~S}$, and expression of inward-rectifying $\mathrm{K}^{+}$increased conversely (Jin et al., 2013). Subsequently, $\mathrm{H}_{2} \mathrm{~S}$ was found to promote the genes expression, the phosphorylation level of $\mathrm{PM} \mathrm{H}^{+}$-ATPase and $\mathrm{Na}^{+} / \mathrm{H}^{+}$antiporter protein level, which regulates plasma membrane $\mathrm{Na}^{+} / \mathrm{H}^{+}$antiporter system in response to salt stress. Meanwhile, $\mathrm{H}_{2} \mathrm{~S}$ was found to inhibit $\mathrm{K}^{+}$efflux and maintain relatively high $\mathrm{K}^{+} / \mathrm{Na}^{+}$ratio in guard cells of alfalfa to enhance salt stress tolerance. In tobacco, $\mathrm{H}_{2} \mathrm{~S}$ selectively inhibiting $\mathrm{K}^{+}$influx channels played a significant role in the ABA-induced stomatal closure. It is worth noting that $\mathrm{Ca}^{2+}$ participated in the regulation of $\mathrm{K}^{+}$influx by ABA, but not involved in the process of $\mathrm{H}_{2} \mathrm{~S}$-induced stomatal closure (Papanatsiou et al., 2015). Taken all together, the results suggested that $\mathrm{H}_{2} \mathrm{~S}$ might be a critical link in stomatal regulation by its interaction with $\mathrm{ABA}$ via ion channels in the signaling transduction network. Consistently, WRKY transcription factors participating in ABA signaling pathway regulated the $\mathrm{H}_{2} \mathrm{~S}$ signaling pathway in plants under cadmium stress (Liu et al., 2015).

To further exploit the mechanism of $\mathrm{H}_{2} \mathrm{~S}$ on stomatal movement, the patch-clamp technique has been applied to test S-type anion channels in the plasma membrane of guard cells recently. The direct evidence of $\mathrm{H}_{2} \mathrm{~S}$-activating S-type anion channel currents in Arabidopsis guard cells was provided. In addition, the activation of anion currents by $\mathrm{H}_{2} \mathrm{~S}$ was mediated by SLAC1 channels and cytosolic free $\mathrm{Ca}^{2+}$. At the same time, protein kinase OST1 functions in $\mathrm{H}_{2} \mathrm{~S}$-induced activated SLAC1 channel currents (Wang et al., 2016). These electrophysiological results accurately showed $\mathrm{H}_{2} \mathrm{~S}$-induced stomatal closure through numerous ions flow. At this point, the pattern of $\mathrm{H}_{2} \mathrm{~S}$ regulating stomatal closure seems to have a conclusion.

In summary, $\mathrm{H}_{2} \mathrm{~S}$ acting as a switch, adjusts to shut down stomata when plants encounter adverse environment. To find out the exact mechanism of stomatal movement regulated by
$\mathrm{H}_{2} \mathrm{~S}$, the further investigation will reveal the secret of ion channels in vivo, as well as the speed and direction of ion flow through other emerging technologies such as NMT (noninvasive micro-test technique).

Meanwhile, S-sulfhydration of proteins modified by $\mathrm{H}_{2} \mathrm{~S}$ in mammals attracted the attention of researchers. $\mathrm{H}_{2} \mathrm{~S}$ might inhibit L-type calcium currents depending on the sulfhydryl group in rat cardiomyocytes. Presumably, S-sulfhydration of the ion channels in guard cells of plant mediated by $\mathrm{H}_{2} \mathrm{~S}$ will turn out to be a focal point in the near future to unravel the mysteries of stoma shutter button.

Compliance and ethics The author(s) declare that they have no conflict of interest.

Acknowledgements This work was supported by the National Natural Science Foundation of China (31372085 to Yanxi Pei, 31400237 to Zhuping Jin).

Mani, S., Li, H., Yang, G., Wu, L., and Wang, R. (2015). Deficiency of cystathionine gamma-lyase and hepatic cholesterol accumulation during mouse fatty liver development. Sci Bull 60, 336-347.

Jin, Z., and Pei, Y. (2015). Physiological implications of hydrogen sulfide in plants: pleasant exploration behind its unpleasant odour. Oxid Med Cell Longev 2015, 1-6.

Jin, Z., Shen, J., Qiao, Z., Yang, G., Wang, R., and Pei, Y. (2011). Hydrogen sulfide improves drought resistance in Arabidopsis thaliana. Biochem Biophys Res Commun 414, 481-486.

Jin, Z., Xue, S., Luo, Y., Tian, B., Fang, H., Li, H., and Pei, Y. (2013). Hydrogen sulfide interacting with abscisic acid in stomatal regulation responses to drought stress in Arabidopsis. Plant Physiol Biochem 62, 41-46.

Liu, J., Hou, L.X., Liu, G.H., Liu, X., and Wang, X.C. (2011). Hydrogen sulfide induced by nitric oxide mediates ethylene-induced stomatal closure of Arabidopsis thaliana. Chin Sci Bull 56, 3547-3553.

Hou, L., Zhu, D., Ma, Q., Zhang, D., and Liu, X. (2016). $\mathrm{H}_{2} \mathrm{~S}$ synthetase AtD$C D e s$ involves in ethylene and drought regulated stomatal movement. Sci Bull 61, 1171-1175.

Lisjak, M., Srivastava, N., Teklic, T., Civale, L., Lewandowski, K., Wilson, I., Wood, M.E., Whiteman, M., and Hancock, J.T. (2010). A novel hydrogen sulfide donor causes stomatal opening and reduces nitric oxide accumulation. Plant Physiol Biochem 48, 931-935.

Papanatsiou, M., Scuffi, D., Blatt, M.R., and García-Mata, C. (2015). Hydrogen sulfide regulates inward-rectifying $\mathrm{K}^{+}$channels in conjunction with stomatal closure. Plant Physiol 168, 29-35.

Liu, Z., Fang, H., Pei, Y., Jin, Z., Zhang, L., and Liu, D. (2015). WRKY transcription factors down-regulate the expression of $\mathrm{H}_{2} \mathrm{~S}$-generating genes, LCD and DES in Arabidopsis thaliana. Sci Bull 60, 995-1001.

Wang, L., Wan, R., Shi, Y., and Xue, S. (2016). Hydrogen sulfide activates S-type anion channel via OST1 and $\mathrm{Ca}^{2+}$ modules. Mol Plant 9, 489-491.

Open Access This article is distributed under the terms of the Creative Commons Attribution License which permits any use, distribution, and reproduction in any medium, provided the original author(s) and source are credited. 